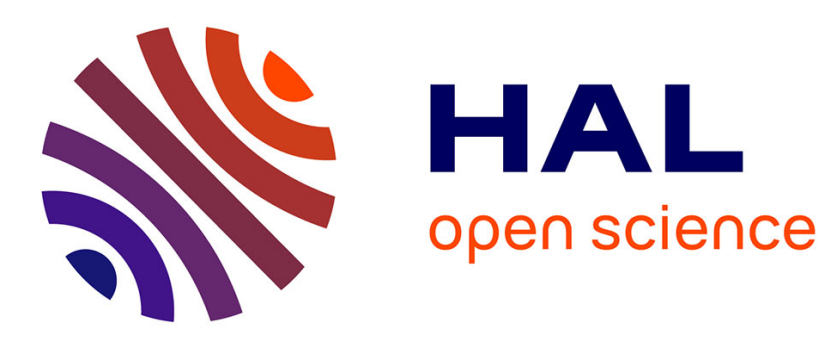

\title{
Microphysics of Hardware or the Gigantism of the Infinitesimally Small
}

Dimitris Ginosatis, Dionyssis Kavvathas, Anastazia Golemi

\section{To cite this version:}

Dimitris Ginosatis, Dionyssis Kavvathas, Anastazia Golemi. Microphysics of Hardware or the Gigantism of the Infinitesimally Small. Marshall McLuhan and Walter J. Ong International Centenary Symposium (The New Sensorium - Embodied Perception, Extensions of Humanity \& Digital Communication), Apr 2012, Athens, Greece. hal-01234444v4

\section{HAL Id: hal-01234444 \\ https://hal.science/hal-01234444v4}

Submitted on 23 Dec 2016

HAL is a multi-disciplinary open access archive for the deposit and dissemination of scientific research documents, whether they are published or not. The documents may come from teaching and research institutions in France or abroad, or from public or private research centers.
L'archive ouverte pluridisciplinaire HAL, est destinée au dépôt et à la diffusion de documents scientifiques de niveau recherche, publiés ou non, émanant des établissements d'enseignement et de recherche français ou étrangers, des laboratoires publics ou privés. 
Marshall McLuhan \& Walter J. Ong

International Centenary Symposium

The New Sensorium: Embodied Perception, Extensions

of Humanity \& Digital Communication, 20-21/04/2012

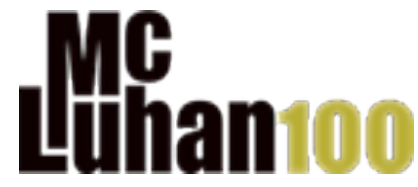

\section{MICROPHYSICS OF HARDWARE OR THE GIGANTISM \\ OF THE INFINITESIMALLY SMALL}

\section{Dimitris Ginosatis - Dionyssis Kavvathas*}

Translation in English by Anastazia Golemi

English version of a lecture (5.000 words) delivered in Greek at the Marshall McLuhan \&Walter J. Ong International Centenary Symposium (The New Sensorium: Embodied Perception, Extensions of Humanity \& Digital Communication), held in Athens, Greece (20-21 April, 2012). The symposium was organized by the Department of Communication, Media \& Culture of the Panteion University of Social \& Political Sciences and its postgraduate programme in Cultural Management, in association with the Coach House Institute and its McLuhan Program in Culture \& Technology at the Faculty of Information (University of Toronto). For further info, see here: http://entopia.org/newsensorium/

Keywords: media technologies, miniaturization, hardware, software, Martin Heidegger, Marshall McLuhan, Harold Innis, Friedrich Kittler, Vilém Flusser.

\section{THE HISTORICAL TRIUMPH OF PORTABILITY}

$\mathrm{T}$ he issue undertaken here is closely related to a process of predominance and subordination, in this case mediotechnological: as already conceived by Marshall McLuhan, wars are nothing but violent rapid defeats of the old technologies caused by the emerging ones or, to put it in slightly different terms, wars are equivalent to accelerated technological changes.

The issue of mobile, portable apparatuses-mechanical extensions of man (if such a McLuhanian metaphor is still valid) has a long history whose succinct reopening may prove particularly productive and enlightening for our current situation, which is worthy of description exactly just because it is decisively determined by technical media.

"Dimitris Ginosatis is Adjunct Assistant Professor (P.D. 407) at the "Digital Arts" Postgraduate Studies Program of the Athens School of Fine Arts.

Dionyssis Kavathas is Assistant Professor at the Department of Communication, Media \& Culture of the Panteion University of Social \& Political Sciences and a Visiting Professor at the "Digital Arts" Postgraduate Studies Program of the Athens School of Fine Arts. 
Without the progressive miniaturization and thus portability of technical media, accentuated in the present era of microchips' architectures, initially on the basis of transistors and later on the basis of millions of integrated flip-flops, it would be impossible to understand the victorious course of laptops, tablets and mobile phones, which are starting to come in proximity to our body skin in such an uncanny way. But let's take things from scratch.

The question reads as follows: unlike trace-engraving techniques on hard materials (such as stone, wood, marble and metals), writing and the book do not only constitute data storage media (which applies to the case of engraving techniques), but also data transmission media. On the statues, for example, information may be engraved, but not transmitted. The fact that, unlike engraving techniques, books like the Torah and the Koran, that is, scriptures of two nomadic peoples, were portable, made the victories on the Greek gods -worshipped in the form of non portable, and for that reason unbearable, marble statues- possible. The latter had always remained synonymous to territoriality and constituted external memory-monument sites, inseparable from their lieu and origin.

However, as McLuhan's compatriot Harold Innis showed in 1950, in his great work titled Empire and Communications, it is not enough for the empires just to manipulate the time axis through mnemotechnological storage techniques, such as engravings on hard materials (inscriptions and statues), but must also triumph over time and space through transmission technologies.

The statue, which according to Hegel is the eminently Greek art form, according to Harold Innis is transformed in a predominantly media problem. The people whose gods looked alive, present in the form of wood or marble, bronze or ivory, were people that felt their gods literally heavier than the nomad livestock farmers' gods, who could easily fly over the sea roads of an empire or over the barren roads of a desert.

In precisely this contrast between localisation/settlement and displacement/movement lies, as pointed out again by Innis, the difference between Athens and Jerusalem, that is, between Greek antiquity and Hebrew civilisation. An opposition based on the difference between settled farmers and nomad pastoralists: the gold and ivory statue of Virgin Athena on the Acropolis used to inform, pointing with her golden spear which direction should the ships follow to berth at the port of Piraeus. Conversely, when the Athenian ships were leaving the place and departed for establishing new colonies in Sicily, the goddess, meaning her statue, remained non-removable, rooted in place, on the Acropolis. On the other hand, sacred media objects that are portable, like holy scriptures, seem to have appeared only to nomads. No longer had the mouths of the divine statues to be washed so that they could speak: the divine orders could now be coded alphabetically.

Hegel, in his lectures on philosophy of history (1821-1831), did not praise Paul and his sea routes, but Muhammad and the Arab "blitzkrieg" wars. In comparison to such data transmission capacity, guaranteed by portable scriptures, the gods "concocted" by the Greek poets are mediotechnologically inferior, to the point that it would be no exaggeration to say, echoing Innis' thesis, that the collapse of the Greek culture was a matter of media efficiency.

Martin Heidegger, in his turn, also insists on the form of the Greek temple and its locality: not accidentally he chooses, in his renowned lecture on "The origins of the work of art" (1935), the emerging from the earth temple or even Van Gogh's shoes, that he does not miss to reinscribe them in the material substratum of the earth. So he considers everything that has lost its site, transferred and exposed beyond its locus of origin, as a betraying translocation and nihilistic unreality. Accordingly, it 
is equally obvious that, for him, a language that has shifted and translated into information bits, transferred via portable computers, marks the removal of the word from the realm of the lived world and thus from its originary truth.

Sacred books, which is no accident that occurred in two nomadic peoples (Hebrews and Arabs), seem to have acquired their sanctity and, subsequently, their dominance over other religions and cultures, from their data storage and transmission operational capacity. Portable books like the Koran and the Torah rendered the stable, localized, heavy temples and statues obsolete. This degradation of fixed monuments and externally localised memory units (or, to translate it in modern terms, this implosion of the hardware and explosion of the software) has widened since in the Roman Empire, after the conquest of Egypt, the monopoly of papyrus was associated with the imperial post (in Latin: cursus publicum).

Rome was no longer dominating only through time storage, but also through transmission, which signaled the domination on space. From that moment on, nothing could stop the arrival of the third sacred writing, the Christian: as we know, Christianity spread through Paul's letters, that functioned as the vehicle of the four gospels and, consequently, as information. Of course, what ultimately led to victory over the Roman empire and the post was the codices (latin) and not the cylindrical scrolls. While ancient writers and readers could handle the volumes as linear memory storage technical devices, unraveling them back and forth with their hands, for the first time the codex allows randomly browsing the material, which, in turn, allows a non-linear, diagonal form of reading/browsing and thus the possibility of rapid access to information, but also another information connectivity option.

This brief retrospect opens for us the historical horizon in which emerges the importance of data storage and transmission techniques, which, as mentioned, signaled the triumph of the portable and rapid information access media, hence the nomadic cultures' triumph over the settled peoples (their holy databases and their users), who in order to be informed had to be present on the spot.

The controversy between settled-down peoples and nomads was decoded in an interesting way by McLuhan as a clash between two different models of perception, respectively based on vision and hearing. In his work titled Understanding Media - The Extensions of Man, he writes that "the world of the ear is more embracing and inclusive than that of the eye can ever be. The ear is hypersensitive. The eye is cool and detached". Here, we should clarify that McLuhan favors the acoustic versus the optical channel, because the acoustic space has no center, negating the distance between the inside and the outside, thus determining the relation between man and his environment haptically.

With the term "haptics" he understands the interplay of senses, which means that the eye is transformed here into hand that closely gropes things up or as we say today, "scans" them, nondetached from them. In this perceptual economy model, people are immersed in the environment. They're directly involved in it. Acoustic haptics is ab out bringing the world closer.

In these observations, it would be useful to remember those of Deleuze \& Guattari, in their attempt to define, in their magnum opus titled Mille Plateaux (A Thousand Plateaus), the art of the nomads as haptic/tactile: for the nomads, the smooth tactile space of vision that is in extreme proximity to things has a key feature: the constant changeability of its direction and points of reference, i.e. the continuous change in the relationship between proximity and distance. Nomadic spaces (the desert, the steppe, the sea) are haptic spaces that allow pure connection. For 
contemporary nomads, such non-Euclidean or fractal spaces are partly the spaces of new digital networks.

\section{NATURAL AND TECHNICAL MEDIA}

In a letter sent in 1971 to the President of his university, Marshall McLuhan writes:

"Dear Claude,

On Sunday I made the biggest discovery of my life. It happened while I was working on the preface for Innis's Empire and Communications, which the university of Toronto press is bringing out [again]. Put in a word, the discovery is this: for 2500 years the philosophers of the Western world have excluded all technology from the matter-form in entelechy treatment. Innis spent much of his life trying to explain how Greek culture had been destroyed by writing and its effects on their oral tradition. Innis also spent much of his life trying to draw attention to the psychic and social consequences of technologies. It did not occur to him that our philosophy systematically excludes techne [art] from its meditations. Only natural and living forms are classified as hylo-morphic". (Letters, 429)

In the above letter, where a major weakness of Western thought, from Aristotle onward, is noted, we read that the philosophers, when dealing with the Aristotelian matter-form entelechy, excluded the technological media and dealt only with living things and the things of the natural world as compositions of matter and form - which is recorded as a separation between nature and logic, between the natural and the technical or artificial.

Ontology systematically excluded technical media of its realm, dealing only with natural media, such as ether, light, water and fire, a fact that in our days led media historians like Fr. Kittler to construct an ontology of media, which will include not only natural but also scientific, mathematically constructed objects, whose existence is due to logical and mathematical sciences: it would be superfluous to recall, for example, that modern computers are fundamentally based on algebras elaborated by Boole, Turing and von Neumann. Similarly, in line with the example of the computer, in antiquity the "arrow" (the projectile) is a scientific object that results from mathematical calculations, as shown by pythagorean philosopher Archytas' studies on ballistics, which Aristotle seems to degrade. For Aristotle, in contrast to Archytas (which shows that there are different traditions and lines of thought in Greek antiquity, which so is not an homogeneous formation), mathematical objects, like all universal logical elements, do not have an existence of their own, because they all stem from abstraction.

As Kittler informs us in an unknown to the public lecture in Tokyo in 2007, titled "Towards an ontology of media":

"Aristotle strongly contradicts his atomistic predecessors following whom imperceptibly small images or eidola separate themselves from a given object, travel without finding any resistance through the kenon, the vacuum, in order to finally arrive at the gates of human eyes or ears. No, says the philosopher whose father, not 
coincidentally, was a great king's physician. In the case of hearing, there must be air both between the thing and the eardrum and between the eardrum and the cochlea. In the case of sight, transmission is even more complicated: between the thing and the human iris, whose pretty Aristotelian name, by the way, is bride, there must be air, whereas between the iris and the retina there must be water. As you know, since Empedocles, fire and water, air and earth are the four divine roots from whose loving mixing Aphrodite does not cease to form our harmonic cosmos. Since Leucippus and Democritus, the Greek atomists, this quartet is also one of letters or elements. Aristotle, however, speaks of two elements, namely air and water, as of two "betweens". In other words: he is the first to turn a common Greek word -metaxy, between- into a philosophical noun or concept: to metaxy, the medium. "In the middle" of absence and presence, farness and nearness, being and soul, there exists not nothing any more, but a mediatic relation. [...] Therefore, instead of covering Aristotle with irony and pointless blame, McLuhan should have thanked the greatest Greek coiner of words for his message that there are media, at least natural or physical ones.”

Yet, an important step beyond the Aristotelian theory of "betweenness" has already been accomplished in 1927, in Martin Heidegger's Being and Time, since the eye and the ear are not surrounded anymore by natural media such as air and water, but are equipped with technical media/instruments such as lenses and telephones, a fact that strongly increases the distance from the things of the world.

This is one of the most unknown fundamental moments of the philosophy of media, as we are shown again by Friedrich Kittler, where both the question of proximity and distance as much as that of the gigantism and nanism are central and entwined in an indissoluble way.

In paragraph 23 of Being and Time, Heidegger anticipates McLuhan, as regards the latter's insight that all "environments are invisible", showing via a highly inaccessible writing style, that media render perception possible, while escaping it. Heidegger writes that "[....] Being-in-the-world is essentially spatial..., its associations always take place in a surrounding world", which cannot be perceived as such, because it is the very condition of possibility of perception.

Heidegger continues:

"For someone who, for example, wears spectacles which are distantially so near to him that they are 'sitting on his nose', this useful thing is further away in the surrounding world than the picture on the wall across the room. This useful thing has so little nearness that it is often not even to be found at all initially. Useful things for seeing, and those for hearing, for example, the telephone receiver, have the inconspicuousness of what is initially at hand which we characterized. This is also true, for example, for the street, the useful thing for walking. When we walk, we feel it with every step and it seems to be what is nearest and most real about what is generally at hand, it slides itself, so to speak, along certain parts of our body - the soles of one's feet. And yet it is further remote than the acquaintance one meets while walking at the 'remoteness' twenty steps away on the street" (par. 23). 
Vision lenses, telephones and streets are bridging distances. They are called media, because of this very interlacement of distance and proximity. Thirty seven years later, McLuhan had already provisioned in Understanding Media a chapter on the phone, adding in the last minute another one for the street, in order to gain even greater popularity.

Indeed, as if he had put to prove all those of which Heidegger speaks in Being and Time, McLuhan calls all media extensions of man - from Freud's vision lenses to Heidegger's street. The fact that technical media are not concerned with the things that lie ahead -as natural media do, in the Aristotelian ontology of proximity- but are capable of bringing the distant near us, becomes more than clear in the Heideggerian commentary on the radio, formulated in the same year (1927) that Brecht was trying to define the difference between radio and telephone.

What, then, Heidegger discovers in Being and Time, eight years before Benjamin's theory of tactility, is finally that "an essential tendency toward nearness lies in the being-in-the-world. All kinds of increasing speed which are more or less compelled to go along with today push for overcoming distance. With the 'radio' for example, being-in-the-world is bringing about today dedistancing of the 'world', which is unforeseeable in its meaning for the being-in-the-world, by way of expanding and destroying the everyday surrounding world" (par.23).

In these last words, we could recognize the origin of certain eschatological/apocalyptic approaches like those of Paul Virilio on pollution and destruction of space and time. But here, what worries Heidegger is something else. The radio is not just another one among the daily practices/human extensions, such as vision lenses or telephones, and the reason for that is that it does not simply and latently come in contact with the human surface, but instead it is inexctricably interwoven with the historical-political position of the being-in-the-world (Dasein) as well as with its transformation: via radio, the German people was called in 1939 through the tubes of transistors (Goebbels: "You want the total war?") to fulfill its historical mission, in a race of worldviews (communism, capitalism, semitism, etc.), just like apostle Paul or Muhammad were formerly "called" through the auditory channel, responding to divine voices. Heidegger writes in a 1938 lecture titled "The age of the world-image":

"With this battle of world views modernity first enters the decisive period of its history and probably the one most capable of enduring. A sign of this event is the appearance everywhere, and in the most varied forms and disguises, of the gigantic. At the same time, the huge announces itself in the direction of the ever smaller. We have only to think of the numbers of nuclear physics. The gigantic presses forward in a form which seems to make it disappear: in destructions of great distances by the airplane, in the representations of foreign and remote worlds in their everydayness produced at will by the flick of a switch".

\section{THE BODY OF THE OTHER: SO CLOSE, BUT STILL SO FAR}

This ever-escalating distances reduction and the constant reversibility of the distant and the near, of gigantism and nanism, which is announced through the Heideggerian apocalyptic tone and which is constantly increasing, approaching the infinitely small in contemporary digital technologies, encounters an obstruction, the stumbling block of the digital culture: the materiality of the body. 
The current trend of telematic society, whose aim is as intact and faster as possible production, storage and exchange of information, is not only the implosion/minimizing of distances in space and time, but also of the body. Globalization preached by McLuhan, which equals a gigantism at the microscopic level, where distances are shortened greatly (the "global village"), is repeated in a fractal manner at the level of technologically armoured human corporeality, which is treated, from the very beginning of technological modernity until today's digital technologies, as a source of noise, interference, errors, ambiguities, disfunctions, in short as a troublesome appendix: man is nothing but a factor of stenosis in the aorta of communication networks. This is a difficult problem to resolve, one that is nicely described by the philosopher of media and technologies Vilém Flusser, using the metaphor of an anthill to make a picture of the modern telematically networked society: just like an anthill is a hyperbrain in the form of a mosaic composed of many individual brains of ants, the telematic society is consisted of brains connected to other electronic brains, forming a hyperbrain, which today bears the name "world wide web". However, Flusser points out that the metaphor of the anthill has a limit as in the telematic society there is no "outside": it is global, introverted; it does not ex-plode, but it is undergoing an ever-escalating im-plosion. In this hyperbrain, bodies exist as mere archaic attachments or simple extensions: which means that not only are these technologies external extensions of the human physiology, but that the physiology itself is an extension of network technologies and channels of the telematically organised society. As readily sometime McLuhan himself admits: "man becomes, as it were, the sex organs of the machine world, as the bee of the plant world, enabling it to fecundate and to evolve ever new forms".

If gigantism, according to Flusser, was the final stage of the industrial modernity, whose main ingredients were matter and energy, in our digital age, whose main ingredient according to Norbert Wiener is information, the gigantism's new trend shifts, this time, at the microscopic level, as Heidegger had already argued in 1938 just before the war, matrix of all media, as we saw above.

Following the contemplative path opened up by the latter, in 1985 Flusser acknowledges in his Universe of Technical Images, that the concept of the "enormous" applies to both the macroscopic and the microscopic level. Hence his dictum that "an atom's core can be enormous, even more than a galaxy". Something which without doubt is concerning equally the increasingly compact, portable devices, which tend to shrink "so as to be almost invisible."

This becomes particularly evident in the field of microchips' architecture, where the dominant practice is the continuing miniaturization, which constitutes the new arcanum of biotechnological power. However, it should be noted that here, as in the case of the management of corporeality considered as an inevitable interference and hence uncertainty material factor- there are rather natural limits which appear to prohibit the promise of a miniaturization that would approach the absolute zero dimension. The reason for that is that in the process of miniaturization there is a point beyond which matter (in this case, silicium) appears to undergo a series of non-measurable quantum effects, that hinder the electronic-lithographic inscription of information. Which means, on the one hand, that information cannot exist outside a material form or medium and, on the other hand, that our dominance over nature - our nature included- finds great resistance.

But let us return to the issue of the body, in other words the human hardware, and its arrangement in the telematic society, as thematized by Flusser. For him, implosion and regression of the masses of bodies to co-working brains networks have to do, among other things, with the general irresistible seduction of the infinitesimally small in which Flusser seems to be indulging himself, and 
which he locates at the level of libido. Basically, it is about the cutoff of libido from reproduction, of sex from biology.

In a culture of mass brain networking, it is natural for the pleasure to be localized in the brain rather than at the genitalia. That is the reason why, in another part of his work, he talks about the mass culture that we experience as a kind of oral-anal phase of civilisation: like infants, the modern lovers of gadgets regress between mouth and anus, to the extent that each brain never stops sucking and discarding data, audiovisually, knowing mostly to enjoy through consuming and defecating, putting off the genitals on the sidelines. At this stage, it is as if the distinction between the sexes has not occured. If we add to these Freudian observations those of Jacques Lacan on the existence of "partial objects" like the voice and the gaze and the pleasure associated with them, then we understand the choice of contemporary industry to invest in devices that isolate the voice and the gaze, offering to consumers the opportunity to enjoy endlessly: reducing, shrinking the body to the partial objects of gaze and voice, what is promoted is an asexual pleasure model. Just think of yourselves absorbed in your mobile handset or the computer screen. There may be a future promise of a total synergy of the senses through the development of an integrated system connected directly to the nervous system, but we are still far from such an anthropological condition.

In this sense, Foucault's well-known analysis on the microphysics of power as well as on the ways of penetration of the latter in our body (which means that power is not something external and disciplinary to us, but something intrinsic that has to do with our very constitution as subjects, something that does not mostly suppress, but shapes pleasure models), this Foucauldian analysis should therefore be completed by both a hardware analysis and a libidinal economy, which will deal with the new investments of this biotechnological power on partial objects. Let's remember here again McLuhan, who although was not led to a political economy of media, had already majorly diagnosed that:

"this power of technology to create its own world of demand is not independent of technology being first an extension of our own bodies and senses... But the need to use the senses that are available is as insistent as breathing - a fact that makes sense of the urge to keep radio and TV [or computers] going more or less continuously... Those external extensions of sense and faculty that we call media we use as constantly as we do our eyes and ears and from the same motives".

The new metasexual, restricted in partial objects, corporeality, which is set up and supported by the networks of gadgets and technical equipment (of which we are mere slaves, as Lacan declared in 1975 in front of a microphone, in order to have his voice recorded by a tape recorder and later printed in a book titled Encore), this corporeality has already been seen either eschatologically by Flusser, as a form of liberation from the body weight or, by Virilio, as a new form of biotechnological appropriation, whose purpose is the dissolution not only of the sexual relationship, but also of the sexual act through the telematic condom of the screen.

Incidentally, we should add here, McLuhan wrote about all media except for that of "eros". According to Freud, "eros" is the cultural medium for uniting, as opposed to the death drive that dissolves all connections and unities. The reasonable question, therefore, is whether the new developping sensory organs of "eros", for example the biocybernetic equipments, function for or against "eros". 
Does the reduction and implosion of distances actually produce proximity? Or a genuine closeness would be the one to maintain an irreducible distance within itself, in order to be maintained as such?

What is certain is that within the culture of new media, a new form is emerging, that guarantees pleasure while protecting the user from the other and the opposite sex. What we avoid is the noncomputable risk of his non-mediated presence, although if anything like that could be possible.

Eventually, the body of the other is so close, yet so far away, as close and as uncannily away from us are the spatial dimensions of the integrated circuits inside our desktops.

The erotic investment of cyberspace seems pathogenic only to the one that still believes there is a sexual relationship. Later on after Lacanian psychoanalysis, we began to understand that the relationship between the sexes is realized to the extent of its failure. What one misses then, when he substitutes the disfuctional "physical" sexual relationship for the narcissistic synergy between man and machine (Turing)? When the simulation of the arousal manipulates and governs pleasure in the form of an imaginary one offered through the screen? Could pleasure exist beyond the imaginary screen?

Or maybe, whoever escapes from cyberspace to the "physical eros", to a face-to-face, is condemned to rediscover the necessity of imaginary "screens" and thus of interfaces? Weren't there always such interfaces (such as literature, painting, poetry, lately photography and cinema, rock music and most recently the Universal Computing Machine), that offered and still offer models of sexual experiences?

Perhaps the solution would rather be to optimize the man-machine interface? Finally, wouldn't it be right to argue that, through technology, we end up where we have always been: to the technology of eros or "ars erotica"? Can there be "eros" without the technologies of "eros"? What about "Turing Machine" and its tools? Are they extensions of man or is it man that operates as a sexual organ/extension of the technical media? Finally, what does this new form of coexistence with a digital "bride" or "groom" mean?

For the time being, one thing is certain: the only specified by the computer is an interface which, sadly enough, reduces the body to the gesture of a mouse-click and therefore to the painful state of tendonitis. And let no one raise the objection that in the near future computers will accept orders directly from the mouths of their users, because in this case their tongues will dry out. 